\title{
Saúde do trabalhador público: questão para a gestão de pessoas - a experiência na Prefeitura de São Paulo
}

Sérgio Antonio Martins Carneiro

\section{Introdução}

Estudos sobre a relação saúde e trabalho na área pública brasileira têm dado a conhecer as condições de vida e de trabalho a que estão expostos os servidores públicos. Abrangendo diferentes categorias em diversos níveis da esfera pública, pesquisas têm apontado um sofrimento oriundo das condições ambientais, mas principalmente da organização do trabalho; é o que revelam os trabalhos de Fernandes e outros (2002), que avaliaram o trabalho de agentes penitenciários, de Carneiro (2002), que pesquisou as condições de trabalho nos agentes de saúde pública, de Tavares (2003), que estudou o sofrimento entre servidores do Judiciário, e de Brant e Dias (2004), que estudaram o sofrimento de gestores em empresa pública.

A administração pública, por outro lado, encontra dificuldades e/ou não se apropriou da problemática para responder às demandas na área de saúde do servidor, o que tem redundado em sua pouca intervenção nessa área, embora existam estudos como o de Gehring-Jr e outros (2003), que propuseram um 
modelo de atenção à saúde do trabalhador nos moldes de co-gestão público-privada, para responder às demandas de assistência médica, prevenção de doenças e promoção da saúde do trabalhador da Universidade Estadual de Campinas (Unicamp). Os autores, no mesmo estudo, denunciam: "Este modelo não esgota a discussão e pesquisa sobre decorrências sociais assistenciais e políticas, já que saúde do trabalhador, em espaços submetidos à gerência pública, não tem experiências anteriores no País".

$O$ fato é que existem poucos trabalhos que relatam experiências em desenvolvimento de ações de prevenção de doenças e promoção à saúde dos servidores. Em geral, a perícia médica, por obrigação legal, é a única atividade realizada, ou seja, a "ação no controle" da ausência ao trabalho.

As questões relacionadas à saúde, via de regra, não fazem parte da pauta dos projetos de capacitação gerencial da administração pública, que geralmente opta por organizar serviços médicos que funcionem de forma isolada das políticas de recursos humanos, contribuindo para a construção de concepções e dinâmicas idiossincrásicas.

Este trabalho problematiza questões da relação saúde e trabalho no serviço público, discute a perícia médica e as dificuldades encontradas por gestores públicos, levanta questões relacionadas à gestão dos serviços de saúde do servidor público, à assistência médica e à promoção da saúde.

Por fim, apresenta-se o projeto de saúde do trabalhador público implementado na Prefeitura de São Paulo, no período de 2001 a 2004, que contemplou aspectos de humanização, transparência da atividade pericial, formação do servidor público e promoção de sua saúde.

\section{Doença: um incômodo para o gestor público}

A elevação da ausência ao trabalho, mesmo circunstancial, localizada em determinadas unidades ou concentrada em determinadas categorias, é tida como fruto da "incapacidade" gerencial de controlar. Perguntas como: o que, no ambiente ou na organização do trabalho, está influenciando na ausência ao trabalho, ou por que os trabalhadores não estão motivados para ir ao seu local de trabalho, raramente são feitas, fato que gera considerável estranhamento.

O gestor local, com encargos cada vez mais complexos, relacionados aos projetos políticos e ao funcionamento administrativo-financeiro, e com exigências e orientação voltadas para resultados, encontra dificuldades para gerenciar os assuntos relacionados à saúde do trabalhador. Essa situação leva-o a declarar-se incompetente para tal atividade e a optar por considerar saúde como questão a ser resolvida e controlada pela medicina. De preferência, a questão saúde é encaminhada a um serviço médico.

A dificuldade em gerenciar essa questão deve-se também à compreensão de que a avaliação da capacidade laborativa é um conhecimento específico do profissional da saúde, o que reduz os aspectos relacionados à saúde do servidor público a um problema de avaliação médica pericial e favorece os serviços autônomos.

Em contrapartida, a área administrativa responsável pela gestão dos recursos humanos, a depender de políticas de governo, sofre tentações para intervir no ato técnico pericial, cria mecanismos administrativo-burocráticos para dificultar o acesso à avaliação médica, exige maior "rigor" aos peritos, estabelece diversos 
procedimentos para dificultar a concessão de licenças médicas e aposentadorias, o nexo de acidentes e doenças do trabalho. Iniciativas essas com o intuito de diminuir o absenteísmo, sem que isso possa significar melhoria da saúde ou da qualidade de vida e trabalho do servidor público.

A idéia do servidor como fraudador de licenças médicas é muito propagada na administração pública e, facilmente, as exceções possibilitam a edição de regras e normas restritivas de direitos para todos. A essa imagem soma-se a do inoperante, identificado por França (1994) como "trabalhadores detestados pela maioria e objeto constante de piadas para muitos" e por Codo (2001), em seu artigo sobre pesquisa realizada pelo Laboratório de Psicologia da UnB em um órgão público do Distrito Federal, nos seguintes termos: "Todos nós temos certeza que o mundo seria melhor se as coisas simples fossem resolvidas de forma simples. Parece ao cidadão comum que o servidor público é um 'ser' dotado da misteriosa propriedade de tornar difícil o que seria fácil, de criar dificuldades ao invés de resolver problemas; um carimbo, uma assinatura, adquire surpreendentemente o dom de se transformar em uma epopéia interminável".

O servidor público brasileiro possui, portanto, uma imagem estereotipada, com forte apelo negativo, que vem ocasionando perda de prestígio social e gerando baixa estima e conseqüente adoecimento.

Essa imagem é reforçada por uma concepção existente na sociedade atual de que cada indivíduo pode e deve ser responsável pela sua saúde, já que é um produto adquirível ao alcance de todos. $\mathrm{O}$ trabalho de Nogueira (2001) critica a higiomania - obsessão pela saúde ou adoração pelo corpo - e considera que existe, na sociedade contemporânea, um movimento autonomista de saúde que vende a idéia de saúde como bem alcançável, desde que o indivíduo adote certos hábitos, siga normas corretas de estilo de vida e evite riscos advertidos. Essa imposição da sociedade de consumo, vale ressaltar, limita a compreensão sobre as diferenças entre os indivíduos, dado que não reconhece o adoecer como condição inerente ao ser humano.

"Setores responsáveis pelasáreas de perícia, assistênciamédica, sauide e segurança (promoçãoàsanide) no setor público, em geral, são separados administrativamente, o que dificulta a elaboração de políticas de sauide do servidor mais amplas".

As doenças, particularmente aquelas desencadeadas ou agravadas pelo trabalho, são comumente tidas como controláveis pelo próprio trabalhador. É como se a doença fosse, de alguma forma, voluntária e reveladora de indivíduo passivo, que tem de se desculpar pelo seu adoecer. Esse tipo de culpabilização estende-se ao acidentado quando se dá a análise do acidente de trabalho pelo 
método do ato inseguro e da prevenção sustentada por equipamentos individuais. São por esses motivos que o trabalhador, em sua maioria, não quer falar do seu adoecer e cria mecanismos defensivos para mascarar e ocultar o seu sofrimento. Como afirma Dejours (1988), existe "A reticência maciça em falar da doença e do sofrimento. Quando se está doente, tenta-se esconder o fato dos outros, mas também da família e dos vizinhos". Aquele que reconhece a sua limitação pode ser considerado um fraco e tornarse um incômodo, particularmente no serviço público.

A compreensão de que os trabalhadores podem ter domínio e controle do seu corpo e, principalmente, da mente é comum no mundo do trabalho. Instituições como as policiais, que apresentam problemas organizacionais complexos e persistentes, reagem de forma defensiva e repressora por ocasião do aparecimento do adoecer. A pesquisa realizada entre os policiais civis do Rio de Janeiro (Assis, 2003) revela aspectos da dinâmica de produção do sofrimento mental relacionado ao trabalho hierarquizado.

\section{A organização de serviços de saúde do servidor público}

Comparativamente, o serviço público investe mais no "controle individual" do absenteísmo que nas ações coletivas de saúde, que aparecem como experiências isoladas, produzindo pouco impacto e padecendo da descontinuidade administrativa, que caracteriza boa parte das políticas públicas. Os setores responsáveis pelas áreas de perícia, assistência médica, saúde e segurança (promoção à saúde) no setor público, em geral, são separados administrativamente, o que dificulta a elaboração de políticas de saúde do servidor mais amplas.

A administração pública vive constantemente a questão de onde localizar a área responsável pela perícia médica, pela assistência e por ações de prevenção de doenças e promoção à saúde do servidor, se no quadro da saúde ou no da gestão de pessoas, razão pela qual é constante a movimentação da estrutura entre as secretarias de saúde e as de administração/gestão. No Estado de São Paulo, por exemplo, o Departamento de Perícias Médicas do estado é vinculado à Secretaria de Estado da Saúde e, no município, o Departamento de Saúde do Servidor é da estrutura da Secretaria Municipal de Gestão, mas a assistência médica é prestada por uma autarquia hospitalar vinculada à Secretaria Municipal de Saúde.

Vincular as ações de saúde do servidor público, atividades tipicamente de gestão de pessoas, à área responsável pela assistência de saúde da população em geral tem ocasionado dificuldades suplementares e, constantemente, conflitos sobre competências e uso de recursos financeiros do Sistema Único de Saúde (SUS) na assistência ao servidor, situação problematizada por Gehring-Jr e outros (2003). Vincular administrativamente as ações de saúde do trabalhador às secretarias de Saúde pode representar, portanto, apenas um repasse de atribuições e uma incompreensão sobre a questão.

As questões relativas à saúde do servidor dizem respeito, fundamentalmente, à gestão de pessoas e devem incorporar práticas e concepções de saúde pública, principalmente de saúde do trabalhador, seja na resposta institucional ao atendimento médico, seja na melhoria dos ambientes de trabalho, seja na avaliação pericial para a capacidade laboral. Localizar 
essa área na gestão dos recursos humanos possibilita contato institucional mais amplo com o conjunto das unidades da esfera administrativa, assim como o aporte de recursos específicos.

O distanciamento entre a área de gestão de pessoas e a de saúde do servidor obstaculiza a intervenção sobre o processo saúde-trabalho-adoecer. A perícia médica, como atividade isolada, não possui instrumentos e recursos para intervir no ambiente e nas relações de trabalho, de forma que possa alterar o perfil de morbimortalidade entre os trabalhadores públicos. A perícia médica tem uma indicação ética de preservar o distanciamento entre perito e periciado para a necessária isenção técnica no momento da avaliação, ou seja, ao avaliador da capacidade laborativa não cabe a intervenção no processo saúde-doença.

As questões de saúde do trabalhador estão além das questões médicas, segundo nos aponta Assunção (2003):

"As relações saúde e trabalho não são analisadas baseando-se exclusivamente nos registros médicos, ou no perfil de adoecimento, ou nas taxas de absenteísmo originadas pelas estatísticas oficiais. Embora os indicadores dêem uma idéia do problema, há o risco de tornar tema médico uma questão social que deriva das condições de trabalho, e não das características estritamente biológicas dos indivíduos”.

Ações de saúde do trabalhador: uma realidade ainda distante no serviço público

Consideram-se ações de saúde do trabalhador: medidas de prevenção de doenças e promoção à saúde que visem à melhoria da qualidade de vida e trabalho, incluindo questões relacionadas ao ambiente e à organização do trabalho; direito à informação sobre os riscos e à participação dos trabalhadores nas ações de vigilância aos ambientes; assistência à saúde do trabalhador; identificação e notificação dos acidentes e das doenças relacionadas com o trabalho; formação e capacitação em saúde do trabalhador e políticas de informação para a construção do perfil epidemiológico de morbimortalidade dos trabalhadores.

$\mathrm{Na}$ área de saúde do trabalhador, como bem conceitua Dias (1994), partese da premissa de que "os trabalhadores adoecem e morrem de uma forma igual, compartilhada com o conjunto da população, e diferente, em decorrência de sua inserção em processos de trabalho particulares no processo produtivo". Tal situação exige, portanto, abordagem particularizada para o serviço público, que é o que afirmam Gehring-Jr e outros (2003): “O espaço público precisa ser reconhecido como um ambiente de trabalho que requer intervenções típicas em saúde".

No serviço público, o acesso às informações constitui a primeira grande dificuldade para o desenvolvimento de ações de saúde do trabalhador, visto que não existem dados consolidados sobre a saúde dos trabalhadores públicos. As estatísticas oficiais brasileiras dos acidentes e das doenças relacionadas ao trabalho fornecidas pela Previdência Social, e consideradas com elevada subnotificação (CARMO et al., 1995), excluem todos os funcionários públicos estatutários civis e militares vinculados à União, aos estados e aos municípios.

A inexistência de sistema nacional que consolide informações sobre a saúde do trabalhador público inviabiliza conhecer o perfil epidemiológico dessa categoria, que 
congrega milhões de trabalhadores, fato que dificulta a elaboração de projetos de promoção humana de maior alcance. A dificuldade, entretanto, não se prende exclusivamente à falta de informações. $\mathrm{O}$ fato de haver um vácuo de responsabilização legal pelo não-cumprimento da legislação de saúde e segurança do trabalho favorece um contínuo postergar no cumprimento de legislações trabalhistas para os servidores estatutários, como a realização de exames periódicos.

A legislação atual de saúde do trabalhador, seja ela do Ministério do Trabalho e Emprego, da Previdência Social ou da Saúde, particularmente a da vigilância sanitária, não faz diferença de direitos entre o trabalhador regido pela Consolidação das Leis Trabalhistas (CLT) e o servidor estatutário, ao mesmo tempo que atribui poder de fiscalização sobre as unidades públicas. Entretanto existe evidente descompasso entre as iniciativas no setor privado e as no setor público. $\mathrm{O}$ que $\mathrm{o}$ Estado exige em termos de saúde e segurança do trabalho não se cumpre em relação aos servidores estatutários.

Os programas de Controle Médico e Saúde Ocupacional (PCMSO) e de Prevenção de Riscos Ambientais (PPRA) e os Serviços Especializados em Engenharia de Segurança (SESMT), criticados pelas suas limitações por vários especialistas da área (GEHring-Jr et al., 2003), ainda são uma realidade distante do serviço público e os órgãos de fiscalização, na prática, sentem dificuldade para obrigar as unidades públicas ao cumprimento da legislação ou para autuá-las pelo seu descumprimento.

A descontinuidade de políticas públicas, o desconhecimento da legislação e a pouca participação dos trabalhadores constituem outras dificuldades para a implementação de ações de saúde do trabalhador no serviço público.

Há de se ressaltar que as características entre os trabalhadores do serviço público são bastante distintas. Sobre isso nos alertam Durand e Beltrão (1994): “[...] compõe-se de integrantes de muitas ocupações e profissões (regulamentadas ou não), dos mais diversos níveis sociais de educação e renda, mas que tem em comum o fato de ter (pelo menos) um vínculo de trabalho (temporário ou permanente) com algum órgão do governo”. Esse vínculo, entretanto, não é suficiente para o estabelecimento de uma identidade ou de um sentimento de classe.

O sindicalismo que representa as categorias do serviço público é relativamente recente na história brasileira, possui uma base bem diversificada e disputada entre um grande número de associações e sindicatos. França, em seu livro publicado em 1993, estimava que, nessa época, havia cerca de 400 organizações e com pouca tradição de atuação na defesa da saúde do servidor. No setor público, o Estado (governo) é o próprio patrão, que também possui pouca experiência em negociar com os servidores, resultando, por vezes, em relações diretas e dificultosas.

A falta de reconhecimento do trabalho aparece como uma das principais queixas dos trabalhadores públicos, sentimento captado por Tavares (2003) na sua pesquisa feita com servidores do Judiciário:

"A partir da análise das entrevistas, identifica-se que o não-reconhecimento pelo trabalho compõe-se da idéia segundo a qual o desempenho profissional do servidor não é considerado institucionalmente de forma suficiente, seja por não haver a prática cotidiana do retorno da avaliação da qualidade 
do trabalho, seja pelo fato de a qualidade do trabalho desenvolvido não ser sistematicamente levada em conta para promoções ou acréscimos salariais, em um plano de carreira. Tal aspecto é visto como algo que repercute no bem-estar das pessoas na medida em que frustra, em vários graus, o desenvolvimento de potencialidades profissionais individuais e as expectativas em longo prazo e que não proporciona à pessoa a vivência de ser valorizado por aquilo que faz".

O pouco reconhecimento do trabalho do servidor público, tanto por parte do usuário quanto pelo gestor, gera uma sensação de desvalorização com sinais e sintomas de falência. O mau funcionamento da máquina estatal é sempre acompanhado do adoecimento dos seus operadores, sujeitos a diversos e contraditórios comandos.

Responsabilizar os servidores pelas mazelas do serviço público e, ao mesmo tempo, identificá-los como detentores de privilégios é parte da estratégia construída para fazer a máquina pública desacreditada, a fim de melhor viabilizá-la como administradora de serviços e garantidora da "liberdade do mercado" ou, melhor dizendo, dos ganhos do capital.

\section{Assistência médica ao traba- lhador público: uma questão em aberto}

Pouco se conhece sobre os agravos relacionados ao trabalho que acometem os trabalhadores públicos brasileiros, pois as estatísticas são consolidadas em cada instituição. Dados de morbidade dos servidores do Município de São Paulo, consolidados pela Divisão de Epidemiologia do Departamento de Saúde do
Trabalhador (S̃̃o Paulo (Município). Boletim Epidemiológico, 2004a; 2004b; 2004c; 2005), apontam os transtornos mentais e as doenças do sistema osteomuscular como os grandes problemas de licenças médicas e readaptações funcionais. No tocante à aposentadoria por invalidez (S̃̃O Paulo (Município). Boletim Epidemiológico, 2004c), as principais causas são os distúrbios mentais seguidos pelas neoplasias, com grande predominância para os cânceres de mama.

A inexistência de um sistema integrado entre as informações disponíveis nos diversos municípios e estados impossibilita traçar um perfil de morbidade do servidor público brasileiro. A subnotificação dos acidentes e, principalmente, de doenças relacionadas ao trabalho é ainda maior. Pode-se afirmar que não se conhece de que adoecem e morrem os trabalhadores públicos brasileiros.

A assistência médica ao servidor aparece como um problema a mais para a administração, seja porque não dispõe de nenhum recurso, seja porque tem de administrar os poucos recursos disponíveis.

Vários órgãos públicos, ao longo dos anos, buscaram alternativas próprias para responder a essa demanda. Dados de 2002, colhidos pela Secretaria Municipal de Gestão Pública nas capitais brasileiras, revelaram grande diversidade de formas de responder aos problemas médico-assistenciais dos servidores na administração pública brasileira, com modelos que expressam, por vezes, concepções antagônicas.

As cidades de João Pessoa, Natal, Maceió e Aracaju informaram que não possuíam nenhum tipo de assistência própria e que os servidores utilizavam-se do Sistema Único de Saúde (SUS) ou, por iniciativa própria, de plano privado de saúde. A Prefeitura de Salvador confirmou 
possuir um plano de assistência médica coberto integralmente pela administração, Florianópolis informou ter convênio com empresa privada e a Prefeitura de São Paulo possui hospital próprio. Os descontos em folha realizados pelas prefeituras que adotaram esse sistema variam de $2 \%$ a 3\% sobre a remuneração, alguns dos quais são compulsórios, como em São Paulo, outros são por adesão, como em Porto Alegre. Não há, portanto um modelo único.

A obrigatoriedade legal da assistência médica e o crescimento de servidores regidos pela CLT têm obrigado os gestores a buscar alternativas para suprir a demanda de assistência e cumprir a legislação de saúde e segurança no trabalho. Isso, muitas vezes, estruturando serviços com pouca eficácia, apenas para dar uma resposta legal.

O SUS considera que estabelecer qualquer diferenciação para atender aos servidores públicos contraria os seus princípios. Cabe destacar que o SUS orientou, por meio de suas conferências, o fim dos hospitais de corporações. É fato que poucos seguiram essa orientação, porém alguns hospitais, como o do Servidor Público de São Paulo, abriram suas portas para atendimento à população - nesse caso, o pronto socorro. Entretanto, o SUS não se propõe a realizar qualquer atividade para os servidores, nem apoio aos hospitais dos servidores, nem exames periódicos. Ressalta-se que os servidores são os executores do atendimento à população.

A assistência médica constitui, com a promoção à saúde, os pilares de uma política de atenção à saúde do trabalhador. Em termos de promoção existe uma grande dívida da coisa pública para com os servidores, o que também ocorre com a área assistencial. A administração pública carece de avaliação dos diversos modelos de assistência existentes no serviço público brasileiro, que possibilite a proposição de projetos para os diversos níveis $\mathrm{da}$ Federação e questione o envolvimento do SUS, de modo que se racionalizem os custos e melhore a eficácia do atendimento ao servidor, que é um cidadão a serviço da coisa pública.

\section{Perícia médica: um olhar sobre a capacidade laboral}

A administração pública, como privilegia a lógica do controle burocrático da assiduidade, requisita muito a intervenção da unidade de perícia médica para "resolver o problema" da ausência ao trabalho. A perícia médica, em geral, é uma atividade pouco compreendida, não incorporada às políticas de $\mathrm{RH}$ e tem regulamentação baseada na exceção para prever situações muito particulares e com procedimentos que se tornam cumprimento de regras.

A perícia de avaliação da capacidade laboral realizada nas instâncias do serviço público é uma necessidade estritamente administrativa, obrigatória e de cunho investigatório. Nesse tipo de perícia, cabe ao perito a tarefa de examinar o periciado para o estabelecimento de nexo entre uma limitação e a capacidade para o trabalho, em situação, por vezes, complexa e geralmente limitada a uma única avaliação.

$\mathrm{Na}$ maioria dos órgãos públicos, existem juntas médicas ou serviços exclusivos que funcionam em separado da área assistencial e de promoção à saúde. Avaliam-se os impedimentos, as incapacidades e não existe olhar para as habilidades ou possibilidades. As opções restringemse ao apto ou inapto, ao capaz ou incapaz, 
inválido ou não. A gama de situações intermediárias possíveis que aparecem no momento da avaliação da capacidade para o trabalho encontra dificuldades legais ou operacionais para a sua implementação, como mudar de função ou de local de trabalho, restringir atividades, requalificar ou colocar o servidor em atividade mais condizente com a habilidade e não com a limitação.

A perícia médica, embora seja um ato médico, não pode ser considerada como ação de saúde. Esta consiste em intervenção no processo saúde-doença, seja como assistência individual, para curar, reparar ou amenizar um sofrimento, incluindo os exames, o uso de medicamentos e equipamentos e de todos os tipos de terapia ou reabilitação, seja como prevenção coletiva de danos, incluindo atividades de educação e comunicação.

$\mathrm{Na}$ atividade pericial, não há o aspecto fundamental da ação: a intervenção. $\mathrm{O}$ médico, na função de perito, não aplica o seu saber para alterar a relação saúde-doença e auferir uma solução ao problema de saúde. Os seus conhecimentos estão a serviço de outros interesses, como o de assegurar o exercício de um direito, de esclarecer alguma questão legal ou de defender o interesse público (Estado).

Embora na perícia não exista a escolha do médico, o periciado cria a expectativa de certo envolvimento. Como diz Lacaz (1997), "Todo aquele que procura o médico, busca também amparo e proteção". É difícil para o doente, mesmo na condição de periciado, compreender que o perito é um médico que não faz ação de saúde, que lhe vai examinar, porém sem proximidade.

A relação perito-periciado é, em sua essência, de natureza conflituosa, porque há direitos, deveres e interesses nem sempre convergentes, situação que favorece certa frieza na relação, que, por vezes, torna-se desagregada, desconfiada e afetivamente alterada por uma imagem entre o tirano e o simulador, num tipo de situação em que o periciado não entende a função do perito e este não reconhece o direito do periciado.

Os serviços de perícia médica em que o conflito é a regra criam rotinas estafantes e estruturam espaços físicos com

"A administração

pública, como

privilegia a lógica

docontroleburocrático

da assiduidade,

requisita muito a

intervençãoda

unidade de perícia

médica para'resolver

oproblema'da ausência aotrabalho"

barreiras. Cada caso de simulador descoberto confirma generalizações e visões parciais, que consolidam a concepção do servidor burlador. A administração, por outro lado, espera da perícia certo controle sobre o corpo do trabalhador, de forma a não dificultar o funcionamento da organização pela ausência ao trabalho.

Avaliar a capacidade para o trabalho é uma atividade complexa que, com 
freqüência, gera dúvidas e requer do perito habilidades para abordagem particularizada, que relacione indivíduo, patologia e seu trabalho. O que separa um bom exame pericial de um enquadramento administrativo é quando o primeiro está fundamentado numa interpretação ponderada da anamnese (história clínica), num exame clínico criterioso, em conhecimentos técnicos atualizados de clínica médica e de epidemiologia, para entender o perfil do adoecer na categoria do periciado, em parâmetros ou protocolos técnicos e em informações, que preservem princípios éticos, do médico assistencialista, de especialistas médicos, de outros profissionais da área da saúde e do gerente. É esse conjunto que deve ajudar a formar o parecer do perito, pois o fato de o trabalhador apresentar limitação ou doença não constitui caso de incapacidade ou invalidez, assim como o bem-estar não significa ausência de doença.

A análise pericial tem de estar focada no estado geral de cada indivíduo, para entender a repercussão da patologia no seu processo singular. Forattini (1996) conceitua de forma clara a relação particular do ser humano e o seu adoecer, ao dizer que

“[...] o desenvolvimento da personalidade torna cada indivíduo único ou, se for preferido dizer, uma tentativa não repetida da biosfera. A noção de estado normal encontra-se claramente sujeita a características próprias do organismo e que são essencialmente variáveis. Dentro dessa gama de variações é que está incluída a normalidade, tanto física como fisiológica".

A essas, pode-se acrescentar a normalidade psicológica, contemplando, assim, um espectro ainda maior de problemas para a avaliação pericial.

A perícia médica configura, de fato, uma relação diferenciada na saúde, até mesmo o sigilo médico constitui uma exceção quando se trata de perícia (Código de Ética Médica, art. 102, e Código Penal, art. 19, inciso III). O perito, por dever de ofício, responde à administração pública revelando informações, porém não deve sujeitar-se a demandas administrativas que se contraponham a seu parecer, até porque o perito deve satisfação ao preceito jurídico da autotutela, ou seja, o perito é um servidor com autoridade constituída para chamar a si a responsabilidade de corrigir o ato sob sua alçada.

A desobrigação do sigilo, entretanto, não significa permissão para fazer divulgação. O perito deve revelar à administração somente dados estritamente necessários para garantir o exercício de um direito do trabalhador ou a defesa da coisa pública. $\mathrm{O}$ princípio é de que o perito age em defesa da coisa pública e não contra o periciado.

Os peritos devem agir com isenção e com base em parâmetros técnicos. A parametrização da perícia médica, por meio de protocolos técnicos, oferece aos peritos padrões científicos mais objetivos no momento da avaliação individual, diminuindo a influência dos aspectos subjetivos e pessoais no exame pericial, que comprometem a qualidade da atividade. O exame médico fundamentado em protocolos possibilita o uso pelos peritos dos mesmos critérios para todos os periciados, respondendo, assim, ao princípio da eqüidade e oferecendo também amparo técnico e legal para a defesa da decisão pericial.

Cabe destacar que os protocolos técnicos não constituem um código de posturas rígidas e devem fomentar um 
debate técnico permanente que contemple as atualizações e os avanços da medicina. Ao mesmo tempo, a publicidade dos parâmetros técnicos, com acesso igual a todos os interessados, proporciona transparência saudável à atividade pericial, visto que o conhecimento prévio dos procedimentos a que o periciado será submetido e dos critérios periciais utilizados pelos médicos diminui conflitos atinentes ao resultado da perícia.

A gestão da atividade pericial deve valorizar aspectos relacionados aos parâmetros técnicos, à humanização e às políticas de informação, à capacitação do servidor público e à promoção à saúde, e não se deve confundir com a interferência burocrática que aparenta resultados imediatos, porém causa problemas, como readaptações funcionais, incapacidades precoces e aumento do custo com a assistência.

\section{A questão da promoção à saúde do trabalhador público}

Realizar ações de promoção à saúde, de forma contínua e sistemática, constitui grande desafio para o serviço público, que incorporou a questão da perícia médica como obrigação e da assistência médica como necessidade, porém não entende, não sabe como fazer ou não prioriza a prevenção de doenças, reduzindo a intervenção a mecanismos de controle ao absenteísmo.

A promoção à saúde é definida pela Organização Mundial de Saúde como “[...] o processo de capacitação da comunidade para atuar na melhoria de sua qualidade de vida e saúde, incluindo uma maior participação no controle deste processo [...]. [...] para atingir um estado de completo bem-estar físico, mental e social, os indivíduos e grupos devem identificar aspirações, satisfazer necessidades e modificar favoravelmente o meio ambiente" (CARTA de OTTAWA, 1986).

A promoção à saúde do trabalhador constitui-se de ações que visam a sensibilizar os trabalhadores para a adoção de práticas saudáveis, individuais e coletivas no ambiente de trabalho. Inclui a busca ativa de doenças ${ }^{1}$, a adoção de medidas preventivas e a capacitação para que trabalhadores possam atuar na melhoria da sua qualidade de vida e na do trabalho. A promoção à saúde compreende organizar informações, promover a formação e criar mecanismos de comunicação, pensando na intervenção.

Atuar em promoção à saúde do trabalhador requer sair do foco da doença para o da saúde, significa construir ações que interfiram no ambiente e na organização de trabalho. Importante ressaltar que promoção à saúde não é um conjunto de receitas que devem ser observadas pelo trabalhador. Ela exige envolvimento e responsabilização de diversos atores: a administração, o gestor local, o corpo técnico, os trabalhadores e seus representantes.

$\mathrm{Na}$ área pública, a construção de políticas demanda uma relação possível e necessária entre as áreas de perícia, assistência e promoção à saúde. As informações produzidas na atividade pericial e na assistência constituem instrumentos privilegiados para o entendimento do perfil de morbimortalidade dos trabalhadores e para o desenvolvimento de ações de promoção à saúde. Os bancos de dados periciais e assistenciais podem fornecer informações importantes sobre as patologias mais comuns, por categoria, ou seja, quem adoece e de que se adoece (GASPARINI et al., 2005). Por outro lado, a 
relação entre perícia e promoção à saúde possibilita dar à atividade pericial um caráter de movimento, de intervenção sobre o processo de adoecimento, tirando, assim, a perícia de lugar passivo, situação, muitas vezes, angustiante para o perito.

A existência de informações é a primeira condição para a realização de ações de promoção à saúde que possam intervir sobre o adoecer com eficácia. Identificar trabalhadores que necessitam de medidas de apoio e os locais de trabalho que precisam de mudanças ambientais e organizacionais e estabelecer programas para restituir, melhorar ou manter a capacidade para o trabalho constituem o objetivo da promoção à saúde do trabalhador.

Consideram-se, neste trabalho, como ações de promoção à saúde do trabalhador: a inspeção, os levantamentos e as avaliações ambientais; a implantação e o apoio às Comissões Internas de Prevenção de Acidentes (Cipa); a realização de exames periódicos; as políticas de formação e capacitação em saúde e segurança no trabalho; as ações de educação e prevenção aos acidentes de trabalho; a criação de instrumentos regulares de comunicação, como revistas, boletins, informativos com temas relacionados à saúde e segurança no trabalho; as políticas de requalificação profissional para o servidor readaptado; as campanhas ou os programas de prevenção às doenças ocupacionais de maior prevalência, como as lesões por esforços repetitivos, os distúrbios da voz, as perdas auditivas induzidas por ruído; e a construção de serviços e políticas de prevenção dos distúrbios mentais e comportamentais.

Planejar e realizar ações de promoção à saúde requer a participação dos atores envolvidos. O gestor local, embora tenha responsabilidades legais pelo encaminhamento das questões relacionadas às condições do ambiente de trabalho, tem, na maioria dos casos, pouca autonomia para resolver questões básicas de segurança, entretanto nas questões relativas à organização do trabalho ampliam-se as possibilidades.

O gestor que acompanha de perto o trabalho do servidor a ele subordinado consegue propor medidas negociadas de mudanças no ambiente de trabalho e, principalmente, na organização do trabalho diário, que valorizem o fazer de cada um, aglutinem-se em torno de projetos e estabeleçam vínculos que reforcem compromissos. Em contrapartida, os trabalhadores reduzidos a operadores de procedimentos simplificados incompatíveis com os seus desejos e potencialidades e submetidos a processos de trabalho que não possibilitam vínculos ou que menosprezam a importância do trabalho humano, sem espaço de participação, estão mais sujeitos ao adoecimento. "Regras e ordens sem envolvimento não funcionam nem no exército", como disse Christophe Dejours no Seminário Internacional "O trabalho no século XXI", realizado na Escola Politécnica/USP, em novembro de 2004.

\section{A experiência da Prefeitura de São Paulo}

A experiência na área de saúde do servidor apresentada a seguir foi implementada na Prefeitura do Município de São Paulo, no período de janeiro de 2001 a dezembro de 2004, e integrou um conjunto de inovações de gestão implementadas pela Secretaria Municipal de Gestão Pública (SGP). Destacam-se dentre as iniciativas da SGP: a criação do Sistema de Negociação Permanente (SINP); a construção da Escola de Formação do Servidor; a implantação de um Plano de Cargos, Carreiras e Salários, criando cargos largos; a descentralização da 
gestão de pessoas; o estabelecimento de novo sistema de avaliação de desempenho; e a realização de um censo que atingiu 100.006 servidores.

Cabe ressaltar que a Prefeitura do Município de São Paulo (PMSP) possui 132.909 servidores ativos (SÃo PAUlo (Município). Boletim Epidemiológico, 2005), distribuídos por diversas funções, dispersos nos mais diferentes locais e expostos a inúmeros riscos à saúde. Realiza, por ano, cerca de 83 mil exames para licenças médicas e mais de 600 juntas de aposentadoria por invalidez. No período de 2001 a 2004, realizou 43.200 exames admissionais (S̃̃o Paulo (Município). Balanço 2001-2004).

A criação, no primeiro semestre de 2001, do Departamento de Saúde do Trabalhador Municipal (Desat), oriundo da unificação do Departamento Médico, de cunho basicamente pericial, com a Divisão de Engenharia e Segurança, que tinha como demanda principal a concessão de adicionais de insalubridade, constituiu-se na primeira iniciativa de integrar ações de promoção à perícia médica. Criou-se, ao lado da Divisão de Perícias Médicas, uma Divisão de Promoção à Saúde e uma de Epidemiologia e Informação.

A inauguração de unidades descentralizadas do Desat, em conjunto com o Hospital do Servidor Público Municipal (HSPM), funcionando com atendimento em clínica médica, ginecologia, pediatria e odontologia, ampliou a relação para além da perícia e da promoção à saúde, incluindo, assim, a área de assistência médica.

O projeto de mudanças contou com o apoio de consultorias, de técnicas de planejamento estratégico e de um portal eletrônico para acompanhamento dos projetos.
Os quatro projetos que nortearam o Desat, no período de 2001 a 2004, foram:

1) Humanização, agilização e transparência dos procedimentos;

2) Descentralização de atividades e serviços;

3) Implementação de ações de promoção à saúde do servidor municipal;

4) Formação e capacitação em saúde do trabalhador.

\section{Humanização}

A humanização do atendimento em saúde na rede pública é sempre um desafio e, tratando-se de perícia médica, adquire dimensões maiores. A implantação desse projeto requereu mudanças em práticas consolidadas, o estabelecimento de novas rotinas, a movimentação de peritos, a implementação de novas tecnologias e de políticas de informação e comunicação, a constituição de fóruns de decisão e, principalmente, a capacitação dos recursos humanos do departamento.

Destacam-se as seguintes medidas:

- Agendamento telefônico das perícias, que eliminou deslocamentos desnecessários e a falta ao trabalho motivada por procedimentos administrativos.

- Serviço de Atendimento ao Usuário ( $S A U)$, que possibilitou o fornecimento de informações seguras e rápidas dos procedimentos a serem observados pelas unidades de RH e pelos servidores.

- Acolbimento do ingressante, realizado em grupo por equipe multiprofissional, fornecendo informações sobre exames médicos de ingresso e atividades realizadas pelo Desat. Foram acolhidos 28.557 ingressantes até dezembro de 2004.

- Melhoria das condições de trabalho, realizada pela instalação de unidades novas e reformadas, com móveis novos e consultórios segundo os padrões das normas sanitárias 
(pia, piso lavável e metragem parametrizada). A mudança da sede central, local de difícil acesso, para o centro da cidade constituiu um marco do novo departamento.

\section{Transparência}

Uma das principais queixas da administração e dos servidores em relação ao antigo Departamento Médico referia-se a falta de transparência, expressa no desconhecimento quanto aos critérios utilizados no momento da avaliação pericial, na falta de uniformidade da atividade técnica, no desconhecimento de procedimentos internos e na dificuldade de acesso às informações periciais.

As medidas tomadas foram:

Protocolos médicos de ingresso, licenças médicas e aposentadoria por invalidez.

Os protocolos foram construídos com a contribuição de diversos especialistas em diversas áreas e foram consultados documentos técnicos atualizados e normas de outros países, o que se somou à experiência adquirida pelos peritos ao longo de vários anos no Departamento Médico pericial.

Foram publicados, no Diário Oficial do Município (Protocolo Técnico..., 2002, 2003, 2004), os parâmetros utilizados na avaliação da perícia médica, explicitando quais os principais critérios de inaptidão nos exames admissionais, nas concessões de licenças médicas e nas aposentadorias por invalidez.

A inexistência de parâmetros técnicos favorecia interpretações baseadas na experiência de cada médico perito, dificultando tratamento equânime e gerando insegurança e desconfiança. A elaboração dos protocolos vem possibilitando a uniformização de procedimentos ao se estabelecerem critérios mais objetivos e técnicos na avaliação da capacidade laborativa.
Cabe ressaltar que a existência de protocolos não é garantia de uniformização de procedimentos. A implementação dos protocolos no dia-a-dia é um processo que requer constante sensibilização dos peritos, para que, sem ferir a autonomia, sejam respeitados os critérios coletivizados, assim como seja realizada uma constante atualização.

\section{Apoio de outros profissionais na avaliação médico-pericial}

As informações fornecidas por outros profissionais não médicos ajudaram a qualificar a perícia do Desat, com destaque para a avaliação fonoaudiológica nos distúrbios da voz dos educadores, a indicação do Centro de Orientação e Apoio Profissional (Coap), nos casos de readaptação funcional, e as sugestões do Grupo de Orientação Terapêutica em Saúde Mental, nos casos que envolvem distúrbios mentais e comportamentais.

Manual de orientações em saúde do trabalhador municipal

A publicação na internet desse manual com informações sobre serviços, legislação e procedimentos do Desat favoreceu a visibilidade dessas informações e agilização dos serviços.

\section{Divisão de epidemiologia e informação}

A criação desse setor possibilitou a edição de boletins epidemiológicos e a organização de bancos de dados mais confiáveis, resultando na melhoria da qualidade da informação fornecida para a administração, para as unidades de recursos humanos, para os sindicatos e para os servidores.. Destaca-se a criação do banco de dados da aposentadoria por invalidez e o de promoção à saúde, além da qualificação do banco da readaptação funcional. 


\section{Agilização}

Redução do tempo de tramitação dos processos de aposentadoria e de readaptação funcional

Com o foco no resultado, em contraposição ao foco no processo, diversas medidas organizacionais foram tomadas no intuito de agilizar a realização de juntas médicas. No período de janeiro de 2001 a janeiro de 2004, a tramitação dos processos de aposentadoria reduziu-se de 120 dias para 47 dias e os de readaptação, de 90 para 47 dias (SÃo Paulo (Município). Balanço 2001-2004).

\section{Mudanças na legislação}

No período de 2001 a 2004, na Prefeitura do Município de São Paulo, ocorreu profunda revisão e atualização da legislação pericial, que era baseada principalmente na exceção e na influência administrativa nas juntas médicas. Dessa legislação, destacamse os decretos de licença médica, ingresso e insalubridade (SÃo Paulo (Município). Decretos... 2001, 2002, 2003, 2004) e as leis de instituição da Cipa (Comissão Interna de Prevenção de Acidentes) e de aposentadoria por invalidez (São Paulo (Município) Lei... 2001, 2002b), além de diversas portarias.

Revisão de processos de trabalho e de fluxos

Foi feita ampla movimentação de pessoal objetivando a introdução das novas diretrizes e a instalação de novos serviços. Saíram do departamento 203 funcionários e entraram 128 funcionários, principalmente de outras categorias da área da saúde para contrabalançar o poder médico. O departamento, que tinha, em janeiro de 2001, um total de 349 funcionários, passou a ter, em dezembro de 2004, 274 funcionários redução de 22\% (S̃̃o Paulo (Município). Balanço 2001-2004).

O Desat realizou também uma revisão nos fluxos de papéis e informações, que resultou em racionalização de procedimentos, eliminação de retrabalhos e desativação dos serviços ociosos (RX, laboratório, EEG), com repasse dos aparelhos para a Secretaria Municipal de Saúde.

\section{Informatização}

Foi instalada, nos diversos setores do departamento, a rede eletrônica da prefeitura associada à aquisição de

\section{"Oacessoàs}

informaçōes constitui

aprimeiragrande

dificuldade no serviço

públicoparao

desemohimentode

açōes de saúde do

trabalhador, vistoque

não existem dados

consolidados sobrea

sauidedostrabalbadores

públicos”.

equipamentos; a relação de um computador para cada 16 servidores passou a ser de 1 para cada 3 (São Paulo (Município). Balanço 2001-2004).

\section{Melhoria no relacionamento com os usuários}

Realização de cursos na área de atendimento ao público, eliminação de barreiras físicas (balcões e guichês), ampliação do horário de atendimento e melhoria da 
qualidade da informação e da orientação prestada aos usuários foram algumas das medidas tomadas.

A redução de chefias intermediárias e a constituição de assessorias (jurídica, de RH e de projetos) favoreceram a aproximação dos usuários com o nível decisório e facilitou a negociação de conflitos. Ao mesmo tempo implantaram-se medidas de apuração e punição de fraudes; anulou-se legalmente, por exemplo, o ingresso de servidores porque foi constatada omissão ou falseamento de informação médica.

\section{Relação com outros órgãos}

Adotou-se uma política de aproximação com as unidades de RH, com os gestores locais e com as entidades sindicais, favorecendo a troca de informações e a redução de conflitos. Vários eventos, como oficinas e reuniões, foram realizados.

\section{Descentralização de atividades e serviços}

O projeto de descentralização do Desat integrou o projeto de descentralização da Secretaria de Gestão Pública e da prefeitura, que culminou com a criação de 31 subprefeituras. O departamento ofereceu aos gestores a opção de gerenciarem as licenças médicas de curta duração (Decreto $\mathrm{n}^{\circ} 42.756 / 02$, alterado posteriormente, em julho de 2005) e repassou a concessão dos adicionais de insalubridade e periculosidade, ficando para o departamento o caráter de instância recursal e normatizadora.

Foi instalado um posto do Desat no Hospital do Servidor Público Municipal (HSPM) para regularizar prontamente a situação funcional dos usuários desse hospital. Foram criadas três unidades próprias nas regiões sul (Santo Amaro), leste (São Miguel Paulista) e norte (Santana), todas integradas com HSPM, responsável pela assistência médica.

\section{Implementação de ações de promo-} ção à saúde do servidor municipal

Realizar ações de promoção à saúde do servidor na rede municipal constituiu-se no maior desafio do Desat, principalmente pelo fato de a rede pública não possuir uma cultura de saúde do trabalhador.

Dentre as ações desenvolvidas na área de promoção à saúde, destacam-se: a criação do Centro de Orientação e Apoio Profissional (Coap), os projetos de intervenção nos ambientes de trabalho, a campanha de sensibilização vocal "A voz é meu instrumento", destinada aos professores, a criação do Grupo de Orientação Terapêutica em Saúde Mental (GOT), a realização de exames periódicos, as análises dos acidentes graves e fatais, as ações de formação e capacitação em saúde do trabalhador e a assessoria às Cipas.

\section{Centro de Orientação e Apoio Profissional \\ O Centro de Orientação e Apoio} Profissional (Coap) foi criado para atender principalmente aos readaptados por problemas de saúde, que somavam, na Prefeitura do Município de São Paulo, 5.993 servidores (S̃̃o PAUlo (Município). Boletim Epidemiológico, 2005). As ações dirigiram-se principalmente aos portadores de distúrbios osteomusculares, transtornos mentais e distúrbios relacionados à voz, que se encontravam subaproveitados e estigmatizados. O Coap foi constituído com uma equipe técnica multidisciplinar para prestar apoio também às unidades locais, aos recursos humanos e à perícia médica do Desat.

O Coap foi estruturado para orientar e apoiar servidores por meio de atendimento individual e grupal. Organizaramse grupos de acolhimento, de orientação 
inicial, de orientação vocal e postural com o objetivo de esclarecer o processo de readaptação, acompanhar o retorno do servidor para sua unidade, propiciar a troca de experiências, orientá-los quanto aos cuidados para a manutenção da saúde vocal e cuidados posturais nas atividades da vida diária e no trabalho. Os casos de saúde mental foram encaminhados para o GOT.

Ao Coap coube orientar e apoiar as unidades de recursos humanos e os gerentes, fornecendo informações sobre o processo de readaptação, formando interlocutores e visitando os locais de trabalho para assessorar na avaliação da atividade laboral e da adequação da relação trabalho-incapacidade.

Ao Coap coube orientar e apoiar também a perícia médica, oferecendo informações sobre o relacionamento dos servidores na unidade de trabalho e fornecendo subsídios para a avaliação e a revisão dos laudos médicos, visando a adequações.

Destaca-se que o Coap criou uma rede de 163 interlocutores, distribuídos pelas 31 subprefeituras existentes à época de sua criação e, no período, realizou 3.787 atendimentos (S̃̃o Paulo (Município). Balanço 2001-2004).

\section{Projetos de intervenção nos ambientes de trabalho}

Os projetos foram elaborados com os objetivos de:

- conhecer os ambientes e as situações de trabalho e identificar os riscos à saúde;

- avaliar a saúde e propor medidas de prevenção individuais e coletivas;

- implantar as Comissões Internas de Prevenção de Acidentes;

- sensibilizar gerentes e trabalhadores para a prevenção de acidentes e doenças relacionados com o trabalho.
A metodologia baseou-se em: levantamento epidemiológico e bibliográfico, reuniões com trabalhadores e gerentes, visitas aos locais de trabalho, análise das atividades desenvolvidas e dos riscos (quantitativa e qualitativa), realização de exames médicos periódicos, aplicação de questionários, palestras e sensibilização para a Cipa, elaboração de um relatório final para os gerentes e representantes dos servidores e uma devolutiva, por meio de reunião, para os trabalhadores.

Os projetos foram desenvolvidos em diversos locais da prefeitura, priorizandose os processos de trabalho com maiores riscos à saúde dos trabalhadores e aqueles que, por demanda espontânea, solicitaram intervenção do Desat. Destaca-se a realização dos projetos envolvendo trabalhadores da Usina de Asfalto, da Guarda Civil Metropolitana, da Educação, do Serviço de Atendimento Médico de Urgência (Samu), do Centro de Zoonoses e de várias subprefeituras, atingindo um total de 6.468 servidores.

Os relatórios $^{3}$ (SÃo Paulo (Município). Relatórios...) revelaram diversas situações de risco e apontaram sugestões. $\mathrm{Na}$ usina de asfalto, por exemplo, $43 \%$ dos exames audiométricos estavam alterados. No Samu, entre os 715 trabalhadores que realizaram exames periódicos, foram encontradas 370 alterações de saúde, com destaque para 139 alterações auditivas, o que redundou na emissão de 62 Comunicações de Acidentes de Trabalho (CAT), principalmente nos motoristas e auxiliares de enfermagem que trabalhavam nas ambulâncias.

O projeto da Guarda Civil Metropolitana (GCM) atingiu 1.381 servidores em 10 unidades, de um total de 5.722 servidores. A categoria da GCM é a com maior índice de acidente de trabalho da 
prefeitura (S̃̃o PAUlo (Município). Boletim Epidemiológico, 2004a). O relatório final e os dados epidemiológicos sinalizaram agravos importantes à saúde física e mental. Esse relatório apresentou propostas de curto, médio e longo prazo, com destaque para: o revezamento nos locais mais penosos, a programação de atividades físicas e de lazer, o apoio psicológico nos casos póstraumáticos, a necessidade de apoio institucional e jurídico aos guardas e familiares, a revisão do trabalho hierarquizado, entre outras. Cabe destacar que foi criada na GCM uma Divisão de Saúde, com equipe multiprofissional, para desenvolver ações no campo da saúde mental e da readaptação funcional. Realizou-se a compra de equipamentos de proteção individual, de armas e de viaturas equipadas, medidas essas sugeridas no relatório final.

\section{Campanha de prevenção}

A campanha "A voz é meu instrumento" foi dirigida aos educadores da rede municipal de ensino, numa parceria do Desat, da Sociedade Brasileira de Fonoaudiologia e do Conselho Regional de Fonoaudiologia/SP. Contou com a participação de 52 fonoaudiólogas e os dados registraram o envolvimento de 17 subprefeituras, 51 pólos de educação, 282 encontros, 5.045 participações de educadores e 6.723 questionários de pesquisa respondidos (Manzoni; Souza 2004).

A campanha, realizada em 2003 e 2004, teve como estratégia a formação de grupos de educadores em três encontros de 90 minutos cada. Realizada de forma regionalizada, teve como conteúdo temas relacionados à saúde vocal (produção vocal, cuidados com a voz e exercícios) e à saúde do trabalhador (fatores de risco e prevenção).

O material educativo produzido ajudou na promoção de discussões sobre os ambientes e as condições de trabalho nas escolas. Os resultados avaliados pelos questionários foram publicados e revelaram, segundo Manzoni e Souza (2004), que "A campanha foi avaliada com satisfação e despertou um forte sentimento de valorização profissional entre os mesmos [...] 67\% tem ou já tiveram alteração na sua voz". Nesse sentido, Souza e outros (2004) ilustram: "os professores relatam maior conscientização quanto ao significado e importância da voz em suas vidas, especialmente na profissão".

Constatou-se, de modo geral, que esses educadores tinham pouca informação sobre as questões relativas à saúde do trabalhador e muitas queixas sobre as condições de trabalho e a saúde vocal. Segundo Manzoni e Souza (2004), "70\% nunca recebeu orientação sobre cuidados com a voz".

\section{Grupo de Orientação Terapêutica em Saúde Mental}

Os distúrbios mentais e comportamentais vêm-se constituindo como um dos principais problemas de saúde do trabalhador (Silva, 2000). Na Prefeitura de São Paulo, excetuando-se as licenças médicas por motivos cirúrgicos, os distúrbios mentais constituem a principal causa de afastamento do trabalho (SÃo Paulo (Município). Boletim Epidemiológico, 2004a).

A criação do Grupo de Orientação Terapêutica em Saúde Mental (GOT) foi uma iniciativa no sentido de intervir no processo de agravamento dos transtornos mentais e na prevenção dos transtornos pós-traumáticos. Com base em uma escuta qualificada, realizada por uma equipe multiprofissional, buscou-se sensibilizar o servidor para a importância de ele se tornar sujeito do seu tratamento, apropriando-se dos recursos disponíveis para a recuperação 
de sua saúde, o que possibilitou a reconfiguração de sua relação com o trabalho.

O GOT foi criado para atender prioritariamente os servidores sem assistência terapêutica, os que estavam em primeira licença por problemas psiquiátricos, os que foram vítimas de algum tipo de violência, como assalto, estupro, assédio ou presenciaram atos de violência e desenvolveram algum tipo de distúrbio póstrauma. Foi estruturado o atendimento individual e em grupo, sem assistência medicamentosa. As visitas aos locais de trabalho e aos serviços de assistência psiquiátrica integraram o conjunto de atividades. O grupo contou com uma supervisão clínica na tentativa de aprimorar o atendimento e reduzir o sofrimento da equipe técnica.

O GOT realizou, no período, 1.670 atendimentos (S̃̃o Paulo (Município). Balanço 2001-2004). A observação dos técnicos do GOT e do Coap é que os servidores que tiveram o apoio do grupo possuíam mais recursos para retorno mais rápido às suas funções.

\section{Exames médicos periódicos}

O Desat, no período de 2001 a 2004, realizou ou supervisionou 11.138 exames periódicos (SÃo PAUlo (Município). Balanço 2001-2004). A avaliação foi baseada em protocolos previamente elaborados, de acordo com as funções exercidas e os riscos aos quais estão expostas as populações estudadas. Constaram dos exames avaliação clínica, exames de acuidade visual, audiometria (nos casos expostos ao ruído), vacinação e outros exames laboratoriais, variando conforme a categoria examinada ou a critério médico.

Todos os casos sugestivos de acidente de trabalho e/ou doença profissional foram orientados para a abertura de
Comunicação de Acidente de Trabalho (CAT) e avaliados pelo referido setor do Desat. Os pacientes que apresentaram alterações por ocasião da avaliação foram encaminhados para tratamento no HSPM, em hospitais do SUS ou de convênios, etc. Nos casos de inaptidão do servidor, foram concedidos a licença médica, o agendamento para readaptação funcional ou a aposentadoria, conforme o caso.

Ao final da avaliação, foi emitido o Atestado de Saúde Ocupacional (ASO) e fornecida a análise dos dados obtidos para a implantação de programas de promoção, de acordo com o perfil epidemiológico encontrado.

A realização de exames periódicos ajudou a identificar, precocemente, inúmeras alterações de saúde e confirmou a importância dessa atividade de prevenção, porém o número de servidores atingidos ainda é muito baixo e não respeita a periodicidade necessária.

\section{Investigação dos acidentes graves e fatais}

Com o objetivo de atuar na prevenção dos acidentes de trabalho, o Desat montou um grupo multiprofissional para atender os casos de acidentes graves e fatais. $\mathrm{O}$ grupo atendeu aos chamados fazendo visita aos locais onde haviam ocorrido os acidentes e, através do método de investigação da árvore de causas, montou relatórios identificando fatores relacionados aos acidentes e indicando medidas de prevenção a novos acidentes.

\section{Formação e capacitação em saúde do trabalhador}

Concretizou-se um grande investimento na área de formação e capacitação em saúde do trabalhador, tanto para os trabalhadores da prefeitura em geral quanto para os servidores do próprio Desat. 
A capacitação e o aprimoramento técnico foi um pilar na estratégia do Desat. Criou-se uma equipe multiprofissional responsável para elaborar ações em educação e uma assessoria de recursos humanos, porém estabeleceu-se que a formação é uma responsabilidade de todos os setores do departamento.

Dentre as diversas ações de formação realizadas no período de 2001 a 2004, destacam-se a capacitação de 1.027 "cipeiros", de 41 turmas do Curso de Formação de Cipa, e a organização de três Seminários de Saúde do Trabalhador Municipal (Sesat), com palestrantes de vários estados brasileiros e a participação de 1.282 participantes. A capacitação foi proporcionada por meio de seminários, cursos, oficinas e ciclos de palestras e atingiu 5.984 trabalhadores (S̃̃o Paulo (Município). Balanço 2001-2004).

Somam-se a essas iniciativas as oficinas de readaptação funcional e de metodologia em saúde do trabalhador, os ciclos de palestras sobre qualidade de vida, os cursos do Programa de Preparação para a Aposentadoria (PPA) e os Encontros de Cipas.

A programação de palestras, seminários e oficinas exclusivamente para os servidores do Desat, assim como a gestão compartilhada por meio de um conselho e de um colegiado fizeram parte das iniciativas de criação de identidade conceitual e envolvimento dos servidores nos projetos por eles executados. Estimulou-se o trabalho em equipe como estratégia para a divisão de responsabilidades.

$\mathrm{O}$ investimento maciço em informática, com a montagem de sala de aula equipada com computadores, no próprio departamento, com cursos ministrados pela Prodam, empresa responsável pela gestão de serviços de informática na prefeitura e que atingiu 442 participações, ajudou na modernização do departamento contra o modelo normativo e serviu como estratégia para a integração entre os diferentes níveis funcionais.

Os servidores do Desat foram constantemente estimulados e liberados para participar das atividades de formação, além de convidados a integrar o planejamento das ações cotidianas, desenvolvendo-se, assim, um processo de educação permanente com temas técnicos e conceituais em saúde do trabalhador.

\section{Desat - uma observação, uma análise}

As ações implementadas no Desat da Prefeitura do Município de São Paulo, no período de 2001 a 2004, foram de caráter estrutural e constituíram outro paradigma. O departamento deixou de ser um órgão pericial com foco na seleção e controle, para se tornar um órgão pericial com parâmetros técnicos, realizador de ações de promoção à saúde e gerenciador de informações epidemiológicas dos fatores causadores de adoecimento. Um órgão modernizado e com relações com outros órgãos da prefeitura, principalmente com as unidades de Recursos Humanos e com o Hospital do Servidor Público Municipal, responsável pela assistência médica.

Dados coletados no Serviço de Atendimento ao Usuário (SAU), na caixa de sugestões e na pesquisa de opinião realizada em 2003 revelaram que houve sensível melhora nas relações interpessoais entre funcionários e usuários, especialmente entre médicos e usuários, apesar da natureza essencialmente conflituosa da perícia médica (SÃo Paulo (Município). Balanço 2001-2004).

A descentralização facilitou o acesso dos servidores, agilizou a concessão de direitos e possibilitou a atuação sobre 
ambientes e condições de trabalho, ao mesmo tempo que ajudou no redesenho do papel do nível central.

As ações de prevenção e promoção à saúde foram importantes no diagnóstico da situação de trabalho de diversos locais e de algumas categorias, assim como na sensibilização e no envolvimento de servidores. Privilegiou-se uma intervenção participativa, estimulou-se um olhar para a proteção coletiva e investiu-se em ações educativas e em parcerias com as unidades de recursos humanos, com o HSPM e com os Centros de Referência em Saúde do Trabalhador.

As ações de promoção à saúde tiveram bom conteúdo, entretanto abrangeram um número insuficiente de servidores, comparando-se com o número total da prefeitura. A morosidade administrativa e a incompreensão de alguns gestores constituíram outros fatores limitantes à implementação de mudanças na organização do trabalho e implantação de medidas coletivas de proteção à saúde dos servidores. Evidenciou-se que promover a saúde no serviço público requer ampla parceria entre gestores e servidores, que, no caso da Prefeitura do Município de São Paulo, são o Departamento de Saúde, as subprefeituras, as secretarias, os gestores, os servidores e os sindicatos.

As iniciativas implementadas pelo Coap na área de readaptação funcional foram importantes e ajudaram servidores, perícia e gestores. Ficou o desafio da implantação de um projeto de requalificação profissional e a alteração na legislação para regularizar o exercício de outras atividades por servidores com limitações de saúde.

As principais questões que merecem tratamento mais adiante referem-se ao modelo de assistência médica, ainda centrada no HSPM e à implantação de política de atenção à saúde do trabalhador, consubstanciada em um projeto com atribuições definidas entre o Desat, os gestores, os servidores e suas representações.

Por fim, cabe ressaltar que as mudanças não ocorreram sem reações de parte dos funcionários do departamento, em especial de alguns setores da perícia, e de alguns gestores em diversos níveis. O envolvimento do corpo gerencial e de boa parte dos servidores do Desat com o projeto, o estabelecimento de regras negociadas e o apoio da administração da Secretaria de Gestão Pública foram decisivos para as realizações previstas no projeto e a sua conseqüente exeqüibilidade.

O Desat mudou de nome e de direção no primeiro semestre de 2005 e chama-se atualmente Departamento de Saúde do Servidor (DSS). Várias iniciativas permaneceram como: o Centro de Orientação e Apoio Profissional, o Grupo de Orientação Terapêutica em Saúde Mental, as unidades descentralizadas, alguns projetos de promoção à saúde, os protocolos técnicos periciais, a campanha "A voz é meu instrumento", entre outras, o que pode gerar outros impactos em médio prazo.

Cabe ressaltar que a mudança registrada na legislação de licença médica de curta duração, em julho de 2005, voltando a centralizar no departamento todo e qualquer tipo de licença, possibilita um retrocesso ao controle burocrático, desqualifica a atividade pericial médica, reforça preconceitos, retira do gestor a possibilidade de intervir na ausência ao trabalho e produz efeitos mediatos na readaptação funcional e nos afastamentos prolongados.

\section{Considerações finais}

A saúde e o adoecer são resultantes de um complexo processo de fatores individuais (genética, hábitos e estilos de 
vida) e coletivos (família, sociedade e trabalho), assim como do acesso aos serviços e recursos tecnológicos de saúde. No âmbito do trabalho, os aspectos relacionados às políticas de gestão (ritmo, intensidade, jornada, valorização, estilo gerencial, entre outros) estão-se tornando mais determinantes para a saúde que as condições físicas ambientais em que a tarefa se desenvolve.

$\mathrm{Na}$ sociedade atual, a vida do homem está cada vez mais presa, pelo corpo e, principalmente, pela mente, ao trabalho, com sensações que variam da satisfação ao ódio, do vício ao desprezo. O sentido do trabalho para cada trabalhador está relacionado a aspectos da subjetividade, não é, portanto, um valor inerente a cada função, é uma construção que acaba por conferir um significado simbólico. $\mathrm{O}$ fato de o trabalho ser público ou privado, criativo ou alienado, de ter uma gestão participativa ou autoritária pode influenciar no adoecimento.

Sobre a relação do homem com seu trabalho, Carneiro (2000) afirma:

"O que possibilita uma relação complementar do homem com o seu trabalho é o fato de este poder ter um sentido individual e social, que transcenda a produção do objeto em si ou o seu valor de uso ou de troca. É necessário, portanto, que o trabalho atenda às necessidades subjetivas do indivíduo e responda aos princípios éticos do coletivo".

Patologias como as lesões por esforços repetitivos, as alterações da voz, os distúrbios mentais e comportamentais, as disfunções gástricas e cardiovasculares e mesmo os cânceres relacionam-se cada vez mais a fatores organizacionais. Os efeitos da organização do trabalho sobre a saúde do trabalhador no mundo globalizado ainda estão por ser devidamente pesquisados. Sobre isso alerta-nos Assunção (2003): "A organização do trabalho, ao atingir o indivíduo, modifica a sua maneira de enfrentar os riscos e traz efeitos sobre a saúde ainda não perfeitamente conhecidos ou dimensionados".

Numa sociedade em que as pessoas não podem adoecer e os servidores são tidos como favorecidos, a ausência ao trabalho, mesmo por motivo de doença, assume uma conotação de privilégio. Mas o grande incômodo com a doença é que, na verdade, ela é reveladora da limitação e da finitude humana e, portanto, deve ser negada para que a instituição apareça como saudável, saneada, bem administrada e com baixo índice de ausência ao trabalho.

A gestão de equipamentos públicos requer qualidades no trato com o outro, exige capacidade para negociação permanente e uma disposição constante para mudanças. A apropriação pelo gestor do tema saúde do trabalhador pode-se tornar importante estratégia, pois possibilita uma intervenção qualificada no absenteísmo, na motivação e no envolvimento dos trabalhadores com o seu fazer e na diminuição dos impactos do adoecer na vida do servidor e da instituição.

O trabalho em que o trabalhador se reconhece como criador ou como parte integrante produz menos adoecimento. As instituições rígidas, com processos criativos reprimidos e baseados na obediência, são freqüentemente geradoras de sofrimentos decorrentes de exigências maiores que os instrumentos pessoais de adaptação e defesa. Espaços coletivos de participação, comunicação e escuta entre chefias, entre chefias e funcionários e entre o serviço e 
seus usuários possibilitam a formação de vínculos que geramresponsabilização a partir de significados.

Gerenciar ações de saúde do trabalhador público pode constituir-se em apoio para a política de recursos humanos, ao propiciar uma aproximação entre gestor e servidores que possibilite um melhor conhecimento dos principais riscos à saúde, uma discussão sobre as prioridades de investimentos e a implementação de ações de promoção à saúde.

(Artigo recebido em dezembro de 2005. Versão final em março de 2006)

\section{Notas}

${ }^{1}$ A busca ativa de doenças requer a investigação de sinais e sintomas precoces, assim como, diagnosticar doença em seu estágio inicial para fins de prevenção de agravamentos ou reparação.

${ }^{2}$ A maior parte das informações consta do Balanço 2001-2004 do Desat. Os dados colhidos nos boletins epidemiológicos do Desat, as pesquisas diretas nos bancos periciais e no Cubo Fopag (folha de pagamento) e as informações do Serviço de Atendimento ao Usuário (SAU) completaram as informações.

${ }^{3} \mathrm{O}$ projeto específico resultou num relatório elaborado pela equipe da Divisão de Promoção, mimeografado, que foi entregue ao gestor e aos trabalhadores.

\section{Referências bibliográficas}

Assis, Simone. Estresse e Sofrimento mental: uma bomba prestes a explodir. In: MinAYO, $\mathrm{M}^{\text {a }}$ Cecília; Souza, Edinilsa (Org.). Missão Investigar. entre o ideal e a realidade de ser policial. Rio de Janeiro: Garamond Universitária, 2003.

Assunção, Ada A. Uma contribuição ao debate sobre as relações saúde e trabalho. Ciência e Saúde Coletiva, Rio de Janeiro, v. 8, n. 4, p. 1005 - 1018, 2003.

Brant, Luiz C.; Dias, Elisabeth C. Trabalho e sofrimento em gestores de uma empresa pública em reestruturação. Cadernos de Saúde Pública, Rio de Janeiro, v. 20, n. 4, p. 942-949, jul./ago., 2004.

Carmo, José C. et al. Acidentes do trabalho. In: Mendes, René (Org.). Patologia do trabalho. Rio de Janeiro: Ateneu, 1995.

Carneiro, Fátima A. A. Condições de trabalho do agente de saúde pública da Sucam (1964-1990), Funasa (1991-2001): uma questão de saúde do trabalhador e coletiva. 2002. Dissertação (Mestrado) - Fundação Universidade Federal de Mato Grosso do Sul.

CARneiro, Sérgio A. M. Trabalho e violência: relação de proximidade. Violência a trabalhadores durante jornada de trabalho, na zona norte de São Paulo, em 1998. 2000. Dissertação (Mestrado) - Faculdade de Saúde Pública da Universidade de São Paulo, São Paulo. 
Carta de Otawa - 1986. In: Brasil. Ministério da Saúde. Fundação Oswaldo Cruz. IEC. Promoção da saúde. Brasília, DF: Ministério da Saúde, 1996.

CoDo, Wanderley. A arte de não fazer. O funcionário público faz o que precisa ser feito? In: Codo, Wanderley; Jaques, M. G. Saúde mental e trabalho: leituras. v. 1. Petrópolis: Vozes, 2001. DiAs, Elizabeth. A atenção à saúde dos trabalhadores no setor saúde (SUS), no Brasil: realidade, fantasia ou utopia?1994. Tese (Doutorado) - Programa de Pós-Graduação em Saúde Coletiva da Universidade Estadual de Campinas.

Dejours, Christophe. A loucura do trabalho: estudo de psicopatologia do trabalho. Trad. de Paraguay A. I. e Ferreira L. L. 3. ed. revista. São Paulo: Cortez, 1988.

Durand, José C.; Beltrão, Ricardo E. V. Recensear funcionários públicos: uma necessidade. Revista do Serviço Público, Brasília, v. 118, n. 2, p. 185-198, 1994.

Fernandes, Rita C. P. et al. Trabalho e cárcere: um estudo com agentes penitenciários da região metropolitana de Salvador/Brasil. Cadernos de Saúde Pública, Rio de Janeiro, v. 18, n. 3, p. 807-816, maio/jun., 2002.

Foratinni, Oswaldo. Epidemiologia geral. 2. ed. São Paulo: Artes Médicas, 1996.

FrançA, Bárbara H. O Barnabé: consciência política do pequeno funcionário público. São Paulo: Cortez, 1993.

. Funcionário público: trabalhador como os outros? Revista do Serviço Público, Brasília, v. 118, n. 2, p.199-212, 1994.

Gasparini, Sandra M.; Barreto, Sandhi M.; Assunção, Ada A. O professor, as condições de trabalho e os efeitos sobre sua saúde. Educaşão e Pesquisa, São Paulo, v. 31, n. 2, p.189199, maio/ago., 2005.

Gehring Jr., Gilson; SoAres, Stuart E.; Corrêa Fo Heleno. Serviços de Saúde do Trabalhador: a co-gestão em universidade pública. São Paulo em Perspectiva, São Paulo, v. 17, n. 1, p. 98-110, 2003.

LaCAZ, Carlos. Temas de medicina: biografia, doenças e problemas sociais. São Paulo: Lemos, 1997.

Manzoni, Claudia T.; Souza, Thelma M. T. Promoção de Saúde. In: Fórum de SAúde do Trabalhador de Araraquara - Distúrbios de Voz Relacionados ao Trabalho, 1. 2004. Anais... São Paulo: Prefeitura do Município de São Paulo; Departamento de Saúde do Trabalhador Municipal, 2004.

Nogueira, Roberto. Higiomania: a obsessão com a saúde na sociedade contemporânea. In: VASCONCELOS, Eymar (Org.). A saúde nas palavras e nos gestos. reflexões da rede educação popular e saúde. São Paulo: Hucitec, 2001.

São Paulo (Município). Decreto no 41.269, de 19 de outubro de 2001. Dispõe sobre a licença médica ao servidor.

licença maternidade.

Decreto $\mathrm{n}^{\circ}$ 41.270, de 19 de outubro de 2001. Dispõe sobre a . Decreto $\mathrm{n}^{\circ}$ 41.285, de 24 de outubro de 2001. Dispõe sobre o exame médico de ingresso.

médica ao servidor.

. Decreto $\mathrm{n}^{\circ}$ 42.106, de 13 de junho de 2002. Dispõe sobre a licença 

médico de ingresso.

Decreto $\mathrm{n}^{\circ}$ 42.180, de 11 de junho de 2002. Dispõe sobre o exame

. Decreto n ${ }^{\circ} 42.138$, de 25 de junho de 2002. Dispõe sobre insalubridade e periculosidade.

. Decreto $\mathrm{n}^{\circ} 42.756$, de 23 de dezembro de 2002. Dispõe sobre a licença de curta duração.

. Decreto $n^{\circ}$ 43.472, de 15 de junho de 2003. Dispõe sobre a licença de curta duração.

. Decreto $\mathrm{n}^{\circ}$ 45.667, de 29 de dezembro 2004. Dispõe sobre a licença médica/consolidada.

. Lei no 13.174, de 5 de setembro de 2001. Institui a Cipa na Prefeitura.

. Lei no 13.379, de 24 de junho de 2002. Dispõe sobre a licença maternidade

especial.

invalidez.

. Lei n ${ }^{\circ} 13.383$, de 3 de julho de 2002. Dispõe sobre a aposentadoria por

- Protocolo Técnico de Exames Admissionais. DOM, de 3.5.2002.

. Protocolo Técnico de Licenças Médicas. DOM, de 27.7.2003.

. Protocolo Técnico de Aposentadoria por Invalidez. DOM, de 16.12.2004.

. Relatório do Projeto Central de Comunicações/Serviço de Atendimento Médico de Urgência (Samu). Desat/Divisão Técnica de Promoção à Saúde. Mimeografado.

. Relatório do Projeto Guarda Civil Metropolitana. Desat/Divisão Técnica de Promoção à Saúde. Mimeografado

. Relatório do Projeto Superintendência das Usinas de Asfalto. Desat/ Divisão Técnica de Promoção à Saúde. Mimeografado.

SÃo Paulo (Município). Secretaria Municipal de Gestão Pública. Departamento de Saúde do Trabalhador. .

. Balanço 2001-2004. São Paulo: 2004.

. Boletim Epidemiológico. Epidemiologia e Informação, São Paulo, jan./ fev., 2004a.

. Boletim Epidemiológico. São Paulo, mar./abr.,2004b.

. Boletim Epidemiológico. São Paulo, jul./ago., 2004c.

. Boletim Epidemiológico. Secretaria Municipal de Gestão, jan./fev., 2005.

SILVA, Flávia P. P. Burnout: um desafio à saúde do trabalhador. PSI - Revista de Psicologia Social e Institucional. v. 2, n.1, jun. 2000.

SouzA, Thelma M. T. et al. A voz é meu instrumento: campanha de sensibilização vocal para educadores do Município de São Paulo. In: Congresso Brasileiro de Fonoaudiologia, 12., 2004, Foz do Iguaçu. Anais... Foz do Iguaçu: 2004. Tavares, Daniela S. O sofrimento no trabalho entre servidores públicos: uma análise psicossocial do contexto de trabalho em um tribunal judiciário federal. 2003. Dissertação (Mestrado) - Faculdade de Saúde Pública, USP, São Paulo. 


\section{Resumo-Resumen - Abstract}

Saúde do trabalhador público: questão para a gestão de pessoas - a experiência na Prefeitura de São Paulo

Sérgio Antonio Martins Carneiro

O artigo trata de questões da saúde do servidor público nos aspectos relacionados à perícia médica, à assistência e à promoção da saúde. Discute-se a saúde do servidor como um problema da área de gestão de pessoas e fazem-se considerações sobre o papel e a gestão da perícia médica realizada nos órgãos públicos, responsável por avaliar nexo entre patologia e capacidade laboral para fins de admissão, licença médica, aposentadoria por invalidez, readaptação funcional, acidente e doenças relacionadas ao trabalho. Ressalta-se a importância da relação entre os serviços de perícia, a assistência médica e a promoção à saúde. Apresenta-se, por fim, a experiência de saúde do trabalhador público realizada na Prefeitura do Município de São Paulo, que trabalhou com os projetos de humanização, agilização e transparência da atividade pericial, de descentralização de atividades e processos, de formação e capacitação em saúde do trabalhador e de implementação de atividades de promoção à saúde.

Palavras-chave: saúde do servidor público, promoção à saúde, perícia médica, gestão pública.

\section{Salud del trabajador público: una cuestión para la gerencia de la gente - la experiencia de la Prefectura de São Paulo \\ Sérgio Antonio Martins Carneiro}

El artículo trata de la salud del servidor público brasileño en los aspectos relacionados con la pericia médica, la asistencia y promoción de la salud. La salud del servidor se discute como problema de la área de gestión de personas. Son hechas consideraciones sobre el rol y la gerencia de la pericia médica desarrollada en los órganos públicos, responsable por evaluar el nexo entre la patología y la capacidad laboral para uso en la admisión, licencia médica, el retiro por invalidez, el reajuste funcional, el accidente y las enfermedades relacionadas con el trabajo. Se destaca, además, la importancia de la relación entre los servicios de pericia, de ayuda médica y de promoción a la salud. Por último, se presenta la experiencia de la salud del trabajador público que se ha realizado en la ciudad de São Paulo - Brasil, que ha trabajado con proyectos de humanización, de agilizacióny transparencia de la actividad pericial, de descentralización de actividades y de procesos, de formación y calificación en la salud del trabajador y de implementación de las actividades de la promoción a la salud.

Palabras-clave: salud del trabajador público, promoción a la salud, pericia médica, gestión pública.

\section{Public workers health: an issue for the personnel management - the experience of the municipality of São Paulo}

Sérgio Antonio Martins Carneiro

The present article deals with Brazilian public workers' health focusing the aspects related to medical evaluation, medical assistance and health promotion. Public workers' health is discussed as a problem related to the Personnel Management area. It analyzes the role played by the medical evaluation departments of public institutions, since they are in charge of evaluating the nexus between disease and labor capacity for the purposes of admission, days-off due to illness, retirement due to illness and work related accidents and diseases. It then highlights the importance of the interaction among the medical evaluation service, the medical assistance and the health promotion. 
It also presents the public workers' health experience in the municipality of São Paulo, which carried out projects to enhance humanization, swiftness and transparency of the medical evaluation activities, to decentralize functions and processes, to build capacity in public workers' health issues, as well to implement health promotion activities.

Keywords: public workers' health, health promotion, medical evaluation, public management.

Sérgio Antonio Martins Carneiro

Médico Sanitarista e do Trabalho. Mestre em Saúde Pública pela USP. Foi diretor do Departamento de Saúde do Trabalhador da Prefeitura de São Paulo.

Contato: <scarneiro@prefeitura.sp.gov.br>/<sergio_carneiro@ ibest.com.br> 